\title{
Myxomycetes associated with pipevine, a temperate liana
}

\section{Coelho $\mathrm{IL}^{1}$ and Stephenson $\mathrm{SL}^{{ }^{*}}$}

${ }^{1}$ Department of Biological Sciences, University of Arkansas, Fayetteville, Arkansas 72701

Coelho IL, Stephenson SL 2012 - Myxomycetes associated with pipevine, a temperate liana. Mycosphere 3(2), 245-249, Doi 10.5943 /mycosphere/3/2/8

Pinevine (Aristolochia macrophylla Lam.), a climbing woody vine native to temperate forests of eastern North America, is morphologically similar to many of the lianas characteristic of moist tropical forests. In August 2010, samples of dead pinevine collected from a study site in the Great Smoky Mountains National Park were used to prepare a series of 50 moist chamber cultures. Thirtyseven of the 50 cultures $(74 \%)$ yielded evidence (either plasmodia or fruiting bodies) of myxomycetes. Fourteen species representing seven genera were recorded, with members of the Trichiales (41\% of all records) and Physarales (49\% of all records) the most abundant.

Key words - Great Smoky Mountains National Park - moist chamber cultures - slime moulds woody vine

\section{Article Information}

Received 13 April 2012

Accepted 19 April 2012

Published online 30 April 2012

*Corresponding author: Steven L. Stephenson - e-mail - slsteph@uark.edu

\section{Introduction}

Woody vines (usually called lianas) are common and often conspicuous features of moist tropical forests throughout the world. However, only recently (Lado et al. 2003, Nieves-Rivera et al. 2003, Wrigley de Basanta et al. 2008, Ko Ko et al. 2010) have the myxomycetes associated with this microhabitat been investigated. Based on the results obtained in the relatively few studies that have been carried out, lianas appear to support a diverse assemblage of myxomycetes. Lianas are not a particularly common feature of the temperate forests of eastern and central North America, but various species of Vitis (grapevine) are consistently present in forests throughout the entire region, especially lowelevation forests that have been subjected to some degree of disturbance. The bark from grapevines has long been recognized as a productive substrate for myxomycetes (e.g., Keller \& Brooks 1976, Everhart et al. 2008).
Pipevine (Aristolochia macrophylla Lam.), also called Dutchman's-pipe, is another climbing woody vine native to eastern North America, where is occurs from Georgia and Alabama to southern Canada. Pipevine, which is much less common than grapevine, is generally associated with relatively moist, midto high-elevation broadleaf forests. Both grapevine and pipevine are morphologically similar to many of the lianas characteristic of moist tropical forests, but this similarity is more apparent for pipevine because of its generally more twining habit and the frequent occurrence of multiple adjacent stems (Fig. 1).

The objectives of the study reported herein were (1) to characterize the assemblage of species of myxomycetes associated with pipevine and (2) to compare this assemblage with those reported in other studies that have examined the myxomycetes associated with tropical lianas. The present study was carried out in the context of an ongoing effort to 
document the myxomycetes of the Great Smoky Mountains National Park as part of the All Taxa Biodiversity Inventory (Landolt \& Stephenson 2007).

\section{Methods}

In August 2010, samples consisting of short (ca 4 to $6 \mathrm{~cm}$ ) sections of dead pinevine were collected from a study site in the Balsam Mountains portion ( $35^{\circ} 32^{\prime} 53^{\prime} \mathrm{N}, 83^{\circ} 10^{\prime}$ '02' $\mathrm{W}$; elevation $1,550 \mathrm{~m}$ ) of the Great Smoky Mountains National Park in western North Carolina. These samples were transported to the laboratory at the University of Arkansas and then used to prepare 50 moist chamber cultures in the manner described by Stephenson and Stempen (1994). The moist chamber cultures consisted of disposable plastic Petri dishes (100 mm diam.) lined with filter paper and containing the sections of dead pipevine. The sample material was moistened with distilled water. After a period of approximately 24 hours, the $\mathrm{pH}$ of each culture was measured using a flat plate electrode and an Orion model $610 \mathrm{pH}$ meter. After $\mathrm{pH}$ had been determined, excess water in each Petri dish was removed. Moist chamber cultures were kept at room temperature $\left(22-25^{\circ} \mathrm{C}\right)$ in diffuse daylight and examined with a stereomicroscope on a regular basis for a period of up to three months. When necessary, a small amount of water was added to each culture to maintain moist conditions. Myxomycete plasmodia and/or fruiting bodies were noted and recorded each time the cultures were checked. All fruiting bodies were removed, air-dried and then glued in small pasteboard boxes for permanent storage. These are deposited in the mycological herbarium (UARK) of the University of Arkansas.

\section{Results}

Thirty-seven of the $50(74 \%)$ moist chamber cultures prepared with samples of pipevine yielded some evidence of myxomycetes (either plasmodia or fruiting bodies). Fourteen species representing seven genera were recorded, with members of the Trichiales (41\% of all records) and Physarales (49\% of all records) the most abundant. In the list that follows, these species are arranged alphabetically by genus and then species. Numbers of collections, along with the $\mathrm{pH}$ recorded for cultures in which the species in question appeared, are indicated in parentheses for each species. In addition, comments are included for any particularly noteworthy or questionable specimens. Nomenclature essentially follows Lado (2005-2012). The abbreviation 'cf.' in the name of a species indicates that the specimen representing the source of the record could not be identified with certainty. This indicates that the material examined was scanty or aberrant.

Arcyria cinerea (Bull.) Pers. (10 records, $\mathrm{pH}$ 6.7-7.8)

Comments - This species is one of the most common and widespread of all myxomycetes (Martin \& Alexopoulos 1969), so its occurrence on all types of lianas would not be unexpected.

Cribraria violacea $\mathrm{Rex}$ (1 record, $\mathrm{pH} 7.0$ )

Licea biforis Morgan (1 record, $\mathrm{pH} 7.0$ )

Lycogala epidendrum (L.) Fries (3 records, $\mathrm{pH}$ 6.7-7. 7)

Perchaena chrysosperma (Curr.) Lister (8 records, $\mathrm{pH}$ 6.6-7.8)

Comments - This species was one of the more abundant species recorded on lianas by Ko Ko et al. (2010) in northern Thailand.

Perichaena depressa Lib. (4 records, pH 6.67.5)

Perichaena quadrata T. Macbr. (4 records, $\mathrm{pH}$ 6.4-6.7)

Perichaena cf. vermicularis (Schw.) Rost. (1 record, $\mathrm{pH} 7.4$ )

Comments - Our identification of this collection is problematic because the material available was both limited and in poor condition. However, the features that could be observed suggest this species.

Physarum cinereum (Batsch) Pers. (4 records, 


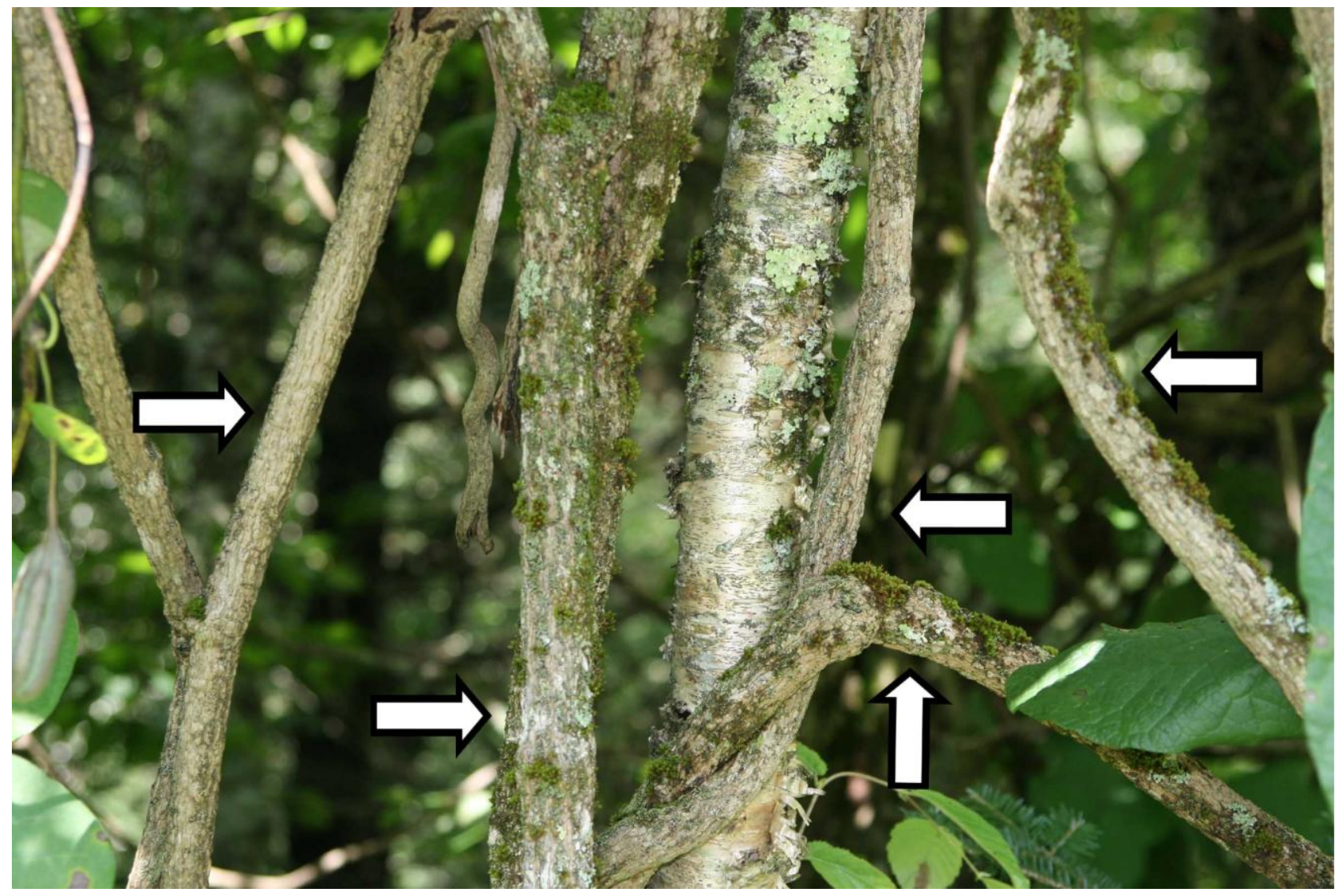

Fig. 1 - Stems of pipevine (indicated by the arrows) in a broadleaf forest in the Great Smoky Mountains National Park.

$\mathrm{pH}$ 6.5-6.7)

Physarum compressum Alb. \& Schwein. (4 records, $\mathrm{pH}$ 6.6-7.3)

Physarum crateriforme Petch (3 records, $\mathrm{pH}$ 7.2-7.3)

Physarum didermoides (Pers.) Rostaf. (6 records, $\mathrm{pH}$ 6.5-7.7)

Physarum pusillum (Berk. \& M.A. Curtis) G. Lister (15 records, $\mathrm{pH}$ 6.5-7.3)

Comments - This species appears to be one of the myxomycetes most commonly associated with the liana microhabitat, based on both the number of collections recorded in the present study and data reported by Wrigley de Basanta et al. (2008).

Stemonitis nigrescens Rex (2 records, $\mathrm{pH} 6.7-$ 7.7)

Comments - Stemonitis nigrescens is not always recognized as distinct from $S$. fusca Roth, but the former commonly occurs in moist chamber cultures, whereas the latter is usually collected in the field, where it is almost invariably associated with coarse woody debris (Martin \& Alexopoulos 1969).

\section{Discussion}

Wrigley de Basanta et al. (2008) reported data for a series of studies of lianas carried out in six different areas of the worldAustralia, Cuba, Ecuador, Mexico, Peru and Puerto Rico. Each of these studies used the moist chamber culture technique to investigate the assemblages of myxomycetes associated with lianas. Numbers of species recovered in a particular study ranged from 15 to $29($ mean $=$ 22 ), and 78 to $100 \%$ (mean $=87 \%$ ) of moist chamber cultures were positive. Ko Ko et al. (2010) carried out a similar study in one area of northern Thailand. They recorded 30 species from a total of 240 moist chamber cultures prepared with samples of dead lianas and living lianas collected at two heights above the ground. For any particular set of samples (e.g., dead lianas near the ground), numbers of species recorded ranged from 10 to $20($ mean $=$ 
13), and the mean percentage of positive cultures was $57 \%$ (range of 43 to 70 ). When all these data are compared with the results obtained in the present study, it appears that the assemblage of myxomycetes associated with pipevine is fairly comparable to those found on lianas in the tropics. Moreover, although the percentage of positive cultures reported in some instances for moist chamber cultures of tropical lianas was higher than the figure $(74 \%)$ we obtained, the latter actually exceeds the percentages reported by Ko Ko et al. (2010). There is one other factor that should be considered in any comparison of data from different studies. In the present study we examined only a single species of liana, whereas it seems very likely that samples were collected from several different species of lianas in each of the studies carried out in the tropics.

The mean $\mathrm{pH}$ for the 50 moist chamber cultures prepared in the present study was 6.8 (range 6.4 to 8.0). Similar data were not obtained in all of the other studies noted above, but the mean $\mathrm{pH}$ was 7.0 (range of 5.4 to 8.5) for those moist chamber cultures for which this parameter was determined. These data suggest that both pipevine and tropical lianas are characterized by a comparable $\mathrm{pH}$. Interestingly, a $\mathrm{pH}$ of 6.8 is relatively higher than the values that have been reported for many of the broadleaf trees that make up the forests in which pipevine occurs (Stephenson 1989, Everhart et al. 2008).

Ko Ko et al. (2010) reported that members of the order Trichiales and Physarales were the predominant myxomycetes occurring on lianas, with the latter making up $71 \%$ of the total number of collections from lianas with rough-furrowed bark. Wrigley de Basanta et al. (2008) indicated that the genus Physarum (which belongs to the Physarales) alone accounted for $29 \%$ of all of the species recorded from lianas. Our data, in which members of the Trichiales ( $41 \%$ of all records) and Physarales (49\% of all records) were the most abundant, certainly conform to this general pattern.

As a general observation, most of the species of myxomycetes associated with lianas in the present study also were reported by Wrigley de Basanta et al. (2008) and/or Ko Ko et al. (2010). The two exceptions were Lycogala epidendrum and Perichaena quadrata. Lycogala epidendrum rarely appears in moist chamber cultures, so the appearance of several small aethalia on samples of pipevine was totally unexpected. Perichaena quadrata is not always recognized as distinct from $P$. depressa, so it is possible that it might have been included with records of the latter species in the other studies.

In summary, pipevine appears to represent a microhabitat for myxomycetes in temperate forests that is not too different from that provided by morphologically similar lianas in tropical forests. Moreover, the assemblages of species involved in each instance are somewhat similar with respect to both abundance and diversity, with many of the same species shared in common.

\section{Acknowledgements}

The research described herein was supported in part by a grant (DLIA2010-03) from Discover Life in America for a project entitled "Diversity of myxomycetes and algae associated with the soils of different forest types in the Great Smoky Mountains National Park."

\section{References}

Everhart SE, Keller HW, Ely JS. 2008 Influence of bark $\mathrm{pH}$ on the occurrence and distribution of tree canopy myxomycete species. Mycologia 100, 191-204.

Keller HW, Brooks TE. 1976 - Corticolous myxomycetes $\mathrm{V}$ : observations on the genus Echinostelium. Mycologia 68, 1204-1220.

Ko Ko TW, Stephenson SL, Hyde KD, Lumyong S. 2010 - Patterns of occurrence of myxomycetes on lianas. Fungal Ecology 3, 302-310.

Lado C. 2005-2012 - An online nomenclatural information system of Eumycetozoa. http://www.nomen.eumycetozoa.com 2012.

Lado C, Estrada-Torres A, Stephenson SL, Wrigley de Basanta D, Schnittler M. 2003 - Biodiversity assessment of myxomycetes from two tropical forest 
reserves in Mexico. Fungal Diversity 12, 67-110.

Landolt JC, Stephenson SL. 2007 Mycetozoans of the Great Smoky Mountains National Park. Southeastern Naturalist 6, 13.

Martin GW, Alexopoulos CJ. 1969 - The Myxomycetes. University of Iowa Press, Iowa City.

Nieves-Rivera A, Stephenson SL, Wrigley de Basanta D. 2003 - Living and dead lianas as a special microhabitat for myxomycetes in tropical forests. Inoculum 54(3), 38.
Stephenson SL. 1989 - Distribution and ecology of myxomycetes in temperate forests. II. Patterns of occurrence on bark surface of living trees, leaf litter, and dung. Mycologia 81, 608-621.

Stephenson, SL, Stempen H. 1994 - Мyxomycetes: a handbook of slime molds. Timber Press, Portland, Oregon.

Wrigley de Basanta D, Stephenson SL, Lado C, Estrada-Torres A, Nieves-Rivera AM. 2008 - Lianas as a microhabitat for myxomycetes in tropical forests. Fungal Diversity 28, 109-125. 